\title{
Vibration Control of Weakly Rigid Casing Based on Gasbag-rubber Damping Flexible Fixture
}

\section{Xiaohua Zhu ( $\nabla$ zxhth113@163.com )}

Southwest Petroleum University

\section{Yao Zhang}

Southwest Petroleum University

\section{Tian Li}

Southwest Petroleum University

\section{Liangliang Dong}

Southwest Petroleum University

Junlei Tang

Southwest Petroleum University

Shengwei Zhang

Southwest Petroleum University

\section{Research Article}

Keywords: Thin-walled casing, Milling vibration, Damping fixture, Aeroengine Dynamic model

Posted Date: September 27th, 2021

DOI: https://doi.org/10.21203/rs.3.rs-935401/v1

License: (c) (i) This work is licensed under a Creative Commons Attribution 4.0 International License.

Read Full License 


\title{
Vibration control of weakly rigid casing based on gasbag-rubber damping flexible fixture
}

\author{
Xiaohua Zhu ${ }^{1 *}$,Yao Zhang ${ }^{1}$, Tian $\mathrm{Li}^{2}$, Liangliang Dong', Junlei Tang ${ }^{3}$, Shengwei Zhang ${ }^{2}$ \\ 1. School of Mechatronic Engineering, Southwest Petroleum University, Chengdu \\ 610500, China \\ 2. AECC Chengdu Engine Co., Ltd., Chengdu 610503, PR China \\ 3. School of Chemistry and Chemical Engineering, Southwest Petroleum University, \\ Chengdu 610500, China \\ "Corresponding author:zxhth113@163.com
}

\begin{abstract}
Combustion chamber casing is a key component of aeroengine, because of its poor rigidity, severe chattering occurs during milling, which seriously affects the surface quality and processing efficiency of the casing, and the existence of geometric nonlinear problems in the machining process makes it difficult to predict machining vibration. Therefore, it is of great significance to study the vibration law of thin-walled casing and reduce machining vibration. Aiming at the problem of vibration control of thin-walled casing, this paper proposes a new type of gasbag-rubber damping flexible fixture, which differ from the ordinary rigid fixture, this fixture has adjustable clamping force and good vibration damping ability. The key factors affecting the vibration response of the thin-walled casing are studied through establishing an equivalent dynamic model of the workpiecefixture system. The research results show that the gasbag-rubber damping flexible fixture can effectively provide support stiffness, which is beneficial to reduce the vibration of the workpiece during processing; According to the actual thickness of different workpieces, the appropriate gasbag pressure is recommended to give play to the vibration damping performance of the fixture; It is recommended that the thickness of the rubber damping block in practice is $8 \sim 12 \mathrm{~mm}$. The research work in this paper has important guiding significance for the design and use of the gasbag-rubber damping flexible fixture, and provides an effective theoretical prediction for the vibration of the thin-walled casing.
\end{abstract}

Keywords Thin-walled casing Milling vibration Damping fixture Aeroengine Dynamic model 


\section{Introduction}

Aeroengine is a highly complex and precise thermal machinery, which is an important thrust to promote the development of aviation industry, and as an important component of aeroengines, the casing has the characteristics of complex structure, small specific gravity, thin wall and high machining accuracy requirements. However, the rigidity of the thin-walled casing is relatively weak, and the traditional rigid fixtures cannot support the inner wall of the casing in a large area. When high milling parameters are used, severe chattering occurs, resulting in serious tool wear and fishscale defects on the surface of the casing(Fig. 1). Therefore, it is of great significance to improve the processing rigidity of the thin-walled casing, reduce the vibration during the processing, and improve the processing efficiency.
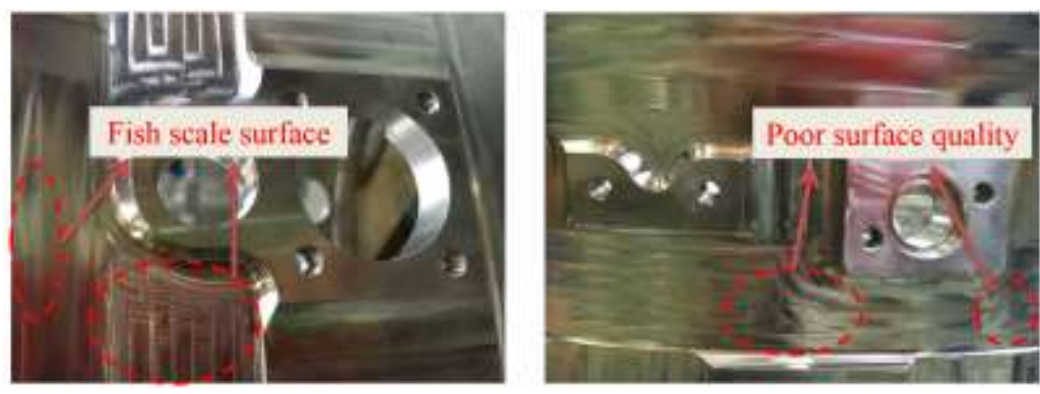

Fig. 1 The surface machining quality defects of thin-walled casing

Combustion chamber casing is a typical thin-walled part, and many scholars have carried out a lot of research on the vibration of thin-walled parts. Evita Edhi et al.[1] and Arnaud et al.[2] established vibration models for thin-wall parts to predict the stability of high-speed milling. I. Anc et al.[3] proposed a spindle-tool model established by finite element method and studied the dynamic behavior of flexible workpiece based on high-speed machining technology. The results showed that the phase of workpiece flutter was related to the cutting conditions and cutting position of the tool. Biermann et al.[4] proposed a milling simulation system that could be used to calculate the regenerative chatter of the workpiece during five-axis milling of turbine blades, and proposed a visual modeling method for the processed surface. Bravo et al.[5] and Campa et al.[6] proposed the stability model of the milling system through a three-dimensional petal diagram.

Selecting reasonable processing parameters can effectively reduce the vibration of the workpiece. After considering the nonlinear characteristics of thin-walled parts, Adetoro et al.[7] predicted the stable region by finite element and Fourier transform method, and realized the vibration reduction of thin-walled parts by selecting reasonable technological parameters (such as spindle speed and chip depth, etc). Rai et al.[8] proposed a validation model of milling process scheme based on finite element method to predict the deformation and elastic-plastic deformation of thin-walled parts by considering the influence of fixture, operation sequence, tool path and cutting parameters. Gao et al.[9] obtained the combination of cutting parameters that directly affect the machining deformation, and proposed a strategy to control the deformation by planning the tool path and an effective compensation method based on modifying the tool point. Bolar et al.[10] conducted full factor $3^{4}$ test on Al 2024-T351, selected appropriate cutting parameters, and conducted variance analysis and regression analysis on the test to determine the influence of process parameters on workpiece roughness. Wang et al.[11] established a recursive optimization model by using particle swarm optimization algorithm and finite element method to optimize fixture and cutting parameters. Milling experiments show that the model can effectively reduce the elastic deformation of thin-walled workpiece during machining. Zhang et al.[12] established the kinematics model of the workpiece coordinate system using the principle of minimum modulus, and established 
a highly linear relationship between machining errors and cutting parameters using neural networks, and then established a cutting parameter optimization model.

The fixture has the ability to balance the cutting force and also plays an important role in the vibration control of thin-walled parts. Therefore, many scholars have done a lot of research on the rational design of fixtures. Qin et al.[13] established a finite element model of multi-fixture layout by considering the clamping force and friction of bracket deformation, and proposed an embedded optimization model aiming at the minimum clamping deformation, which provided a theoretical basis for the layout design of thin-wall fixture. Wan et al.[14] proposed a new analysis method to determine the influence of fixture arrangement on thin-walled multi-frame workpiece in the processing process. Raghu et al.[15] considered the fixture geometry error and clamping problem of part deformation. Ma et al.[16] proposed a flexible fixture based on magnetorheological fluid for milling vibration of thin-walled parts. Dong et al.[17] established a dynamic fixture-workpiece contact model and studied the effect of clamping force on thin-walled parts by finite element method. Selvakumar [18] and Vasundara et al.[19] introduced neural networks and genetic algorithms to optimize the clamping deformation of thin-wall parts and reduce the elastic deformation of the workpiece. Zeng et al.[20] proposed the dynamic model of the work-jig tool system and the jig design method to suppress machining vibration. Kolluru [21] and Wang et al. [22] designed a new flexible fixture to solve the problem of poor rigidity and low damping of the thin-walled casing. Finite element and experiments proved that the new flexible fixture has good vibration damping performance. However, this clamp cannot provide sufficient clamping force and machining rigidity for thin-walled parts.

In summary, although there are many valuable results in the research on vibration reduction of thin-walled casing, it is not enough to control the vibration of the workpiece from the innovative design of the fixture, especially the lack of the design and theoretical calculation basis of the flexible vibration reduction fixture. This paper proposes a flexible fixture based on gasbag-rubber double vibration reduction from the perspective of machining vibration, clamping deformation and machining efficiency of the combustion chamber casing. An equivalent dynamic model of workpiece-fixture was established, and the accuracy of the model was verified by the milling vibration experiment of TRENT-001 casing. The key factors affecting workpiece-fixture system vibration were studied, which has certain guiding significance for the design and on-site application of gasbag-rubber damping flexible fixture.

\section{Working principle of gasbag-rubber damping flexible fixture}

\subsection{Working principle}

In order to improve the machining stiffness of the casing, and meet the requirements of the practical machining application, in this paper, a new type of gasbag-rubber damping flexible fixture is proposed. The fixture has the following advantages:

1. Excellent vibration damping capacity;

2. Easy to mount and clamp;

3. Clamping force can be adjusted;

4. Small clamping deformation.

The working principle of the device: inject air into the gasbag, the gasbag expands to push the nylon to move radially, and finally clamp the workpiece, linear guides installed on the foundation and the pressure plate ensure the radial displacement of the nylon block. Lower T-type pressure plate and the upper pressure plate respectively fix the lower and upper parts of the workpiece to 
restrict its axial displacement. The principle structure of fixture is shown in Fig. 2.

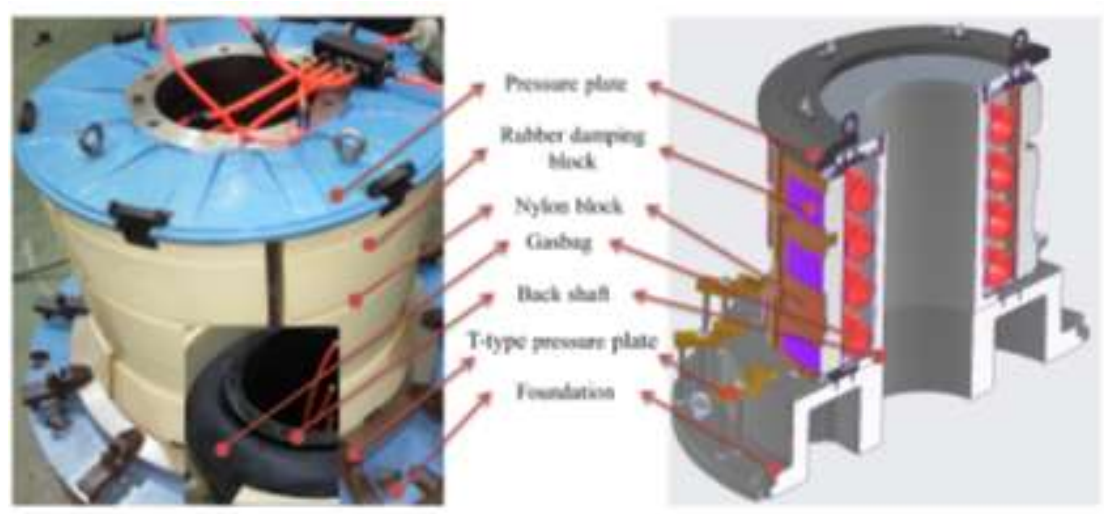

Fig. 2 Schematic diagram of the gasbag-rubber damping flexible fixture

\subsection{Simplified gasbag mechanics model}

According to the similar characteristics of the gasbag model and the spring model, the gasbag is simplified into a spring, and the stiffness coefficient is calculated through the gas balance equation and force analysis(Fig. 3). For the convenience of calculation, it is assumed that the squeezing amount of the inner and outer sides of the gasbag is the same, and the deformation of the upper and lower gasbags is ignored.

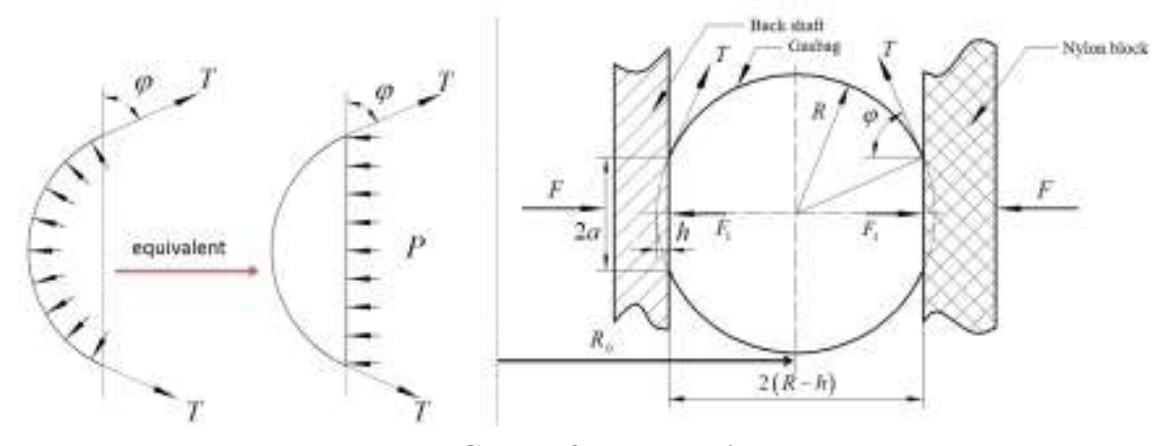

a. Gasbag force analysis
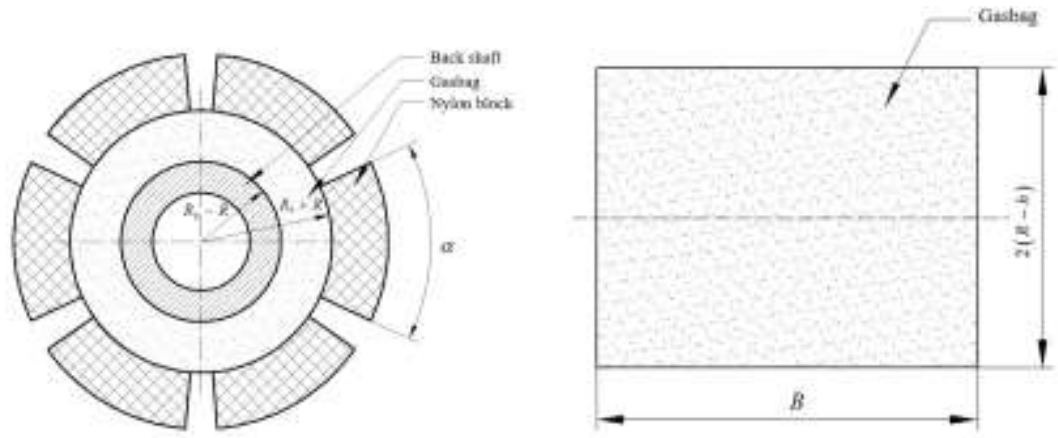

b. Effective contact area with gasbag

Fig. 3 Diagram of interaction between gasbag, back shaft and nylon block

When the initial air pressure of the gasbag is $P_{0}$, it can be obtained from the gas balance equation:

$$
\begin{aligned}
& P V=P_{0} V_{0}=n R T \\
& V=V_{0}-\Delta V \\
& V_{0}=2 R_{0} R^{2} \pi^{2}
\end{aligned}
$$

Where $\Delta V$ is, 


$$
\begin{aligned}
& \Delta V=\frac{\left(B_{1}+B_{2}\right)\left(\pi R^{2} \arctan \left(\frac{a}{R-h}\right)\right)}{180^{\circ}}-\frac{a(R-h)\left(B_{1}+B_{2}\right)}{2} \\
& B_{1}=\frac{\left(R_{0}+R-h\right) \alpha \pi}{30^{\circ}}, B_{2}=\frac{\left(R_{0}-R+h\right) \alpha \pi}{30^{\circ}}, B=2 \pi R_{0}
\end{aligned}
$$

Where $P$ is the gas pressure after gasbag volume compression; $V_{0}$ is the initial gasbag volume; $\Delta V$ is the volume change of the gasbag; $R$ is the diameter of the gasbag; $h$ is the radial compression after the gasbag is inflated; $a$ is the effective contact height between the gasbag and the nylon block; $R_{0}$ is the center distance between the gasbag and the fixture; $B_{1}$ is the effective contact length between the gasbag and the nylon block; $B_{2}$ is the effective contact length between the gasbag and the support ring. $\alpha$ is the central angle of the nylon block, substituting formula(2) into formula(1) can be obtained $P$.

$$
P=\frac{P_{0} \pi^{2} R_{0} R^{2}}{\pi^{2} R_{0} R^{2}-\frac{\pi^{2} \alpha R^{2} R_{0}}{5400^{\circ}} \arctan \left(\frac{a}{R-h}\right)+\frac{\pi \alpha R_{0} a(R-h)}{1800^{\circ}}}
$$

For the force analysis of a single gasbag, the gasbag tension $T$ can be obtained,

$$
T=\frac{P B(R-h)}{\sin \varphi}
$$

Finally, the force $F$ of the gasbag acting on the nylon block is obtained as,

$$
F=2 P B(R-h) \cot \varphi
$$

Where, $\varphi$ is the included angle between the gasbag tension and the horizontal direction.

In order to simplify the calculation complexity, this article assumes that the effective contact area of the gasbag and the nylon block under different pressures is the same, that is, the radial extrusion amount $\mathrm{h}$ of the gasbag is the same.

$$
F=\sum F_{i}=\sum_{i=1}^{N} k_{i} y_{i}
$$

Where, $F_{i}$ is the force of the $i$-th gasbag on the nylon block, $k_{i}$ is the $i$-th stiffness of the spring after the simplification of the $i$-th gasbag, $y_{i}$ is the $i$-th compression amount of the $i$-th gasbag, and $N$ is the number of springs.

\subsection{Double damping equivalent model}

Rubber materials have good damping, sound insulation and cushioning properties, the hysteresis and internal friction characteristics of rubber are usually expressed by loss factors. The larger the loss factor, the more obvious the damping and heat generation of the rubber, and the more obvious the damping effect. Rubber shock absorber is usually equivalent to an elastic spring in parallel with viscous resistance, as shown in Fig. 4.

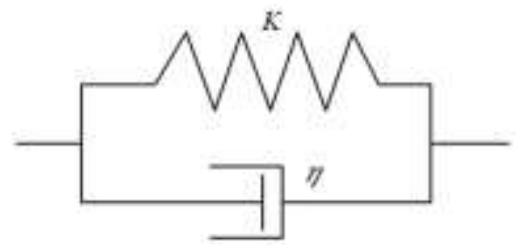

Fig. 4 Equivalent model of rubber shock absorber

Rubber material has three nonlinearities in material, geometry and boundary in the simulation 
process, so it is very important to select an appropriate rubber constitutive model for the accuracy of model calculation. The stress and strain of rubber material were obtained through compression test, and the data fitting showed that Yeoh model could better describe the change of rubber. The Yeoh model [23, 24] adopted in this paper belongs to the reduced polynomial hyperelastic model, and its strain energy expression is:

$$
W_{\text {Yeoh }}=\sum_{i=1}^{N} C_{i 0}\left(I_{1}-3\right)^{i}+\sum_{K=1}^{N} \frac{1}{d_{K}}(J-1)^{2 K}
$$

Where, $C_{i 0}$-Yeoh model constant; $d_{k}$-material constant.

According to the commonly used simplified form of Yeoh equation, $N$ generally takes 3 ; and for incompressible materials, $J$ takes 1 . Then the strain energy expression can be simplified as:

$$
W_{\text {Yeoh }}=C_{10}\left(I_{1}-3\right)+C_{20}\left(I_{1}-3\right)^{2}+C_{30}\left(I_{1}-3\right)^{3}
$$

From the relationship between the kirchhoff stress tensor $t_{i j}$ and the Green strain tensor $\gamma_{i j}$ :

$$
t_{i j}=\frac{\partial W}{\partial I_{1}} \frac{\partial I_{1}}{\partial \gamma_{i j}}+\frac{\partial W}{\partial I_{2}} \frac{\partial I_{2}}{\partial \gamma_{i j}}
$$

After substituting formula(8) into formula(9), and then substituting the relationship $t=\sigma \lambda$, the engineering strain relationship is obtained as:

$$
\frac{\sigma_{1}}{2\left(\lambda_{1}-1 / \lambda_{1}^{2}\right)}=C_{10}+2 C_{20}\left(\lambda_{1}^{2}+\frac{2}{\lambda_{1}}-3\right)+3 C_{30}\left(\lambda_{1}^{2}+\frac{2}{\lambda_{1}}-3\right)^{2}
$$

Using the experimental data obtained by uniaxial compression, and $x=\lambda_{1}^{2}+\frac{2}{\lambda_{1}}-3, y=\frac{\sigma_{1}}{2\left(\lambda_{1}-1 / \lambda_{1}^{2}\right)}$, a quadratic curve can be fitted, where $C_{10}$ is the value of the zero degree coefficient of the curve, $C_{20}$ is $1 / 2$ of the coefficient of the primary term and $C_{30}$ is $1 / 3$ of the coefficient of the quadratic term of the curve. The final rubber constitutive material parameters measured according to the test are: $C_{10}=7.17, C_{20}=-5.63, C_{30}=3.04$. Damping properties were given to rubber by Rayleigh damping model.

The schematic diagram of the principle of double vibration attenuation of fixture is shown in Fig. 5, the vibration generated in the processing process is first absorbed and dissipated by the damping components, and then the vibration is transmitted to the gasbag, and then absorbed and dissipated by the gasbag, so as to achieve the effect of double vibration reduction of fixture.

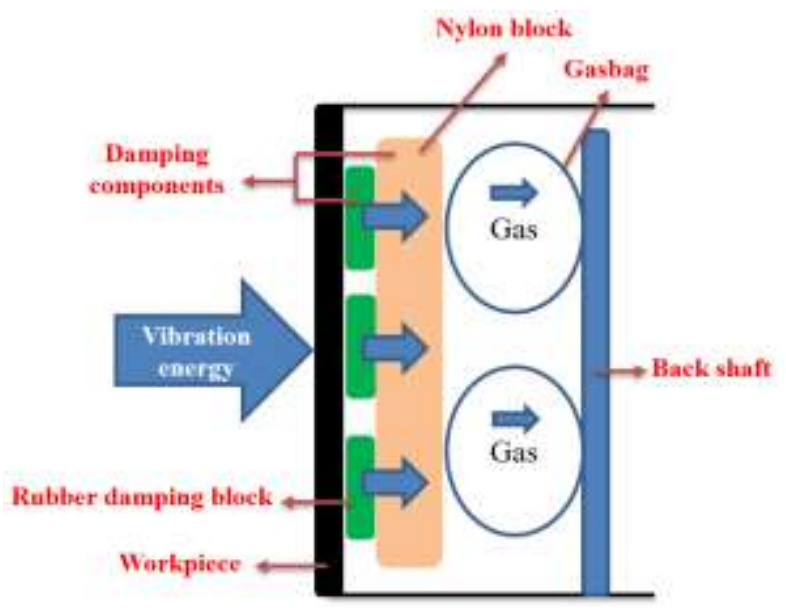

Fig. 5 Schematic diagram of vibration double attenuation

The rubber damping block and the nylon block are equivalently integrated, that is, the damping component. The mass of the gasbag has little effect on the vibration of the system, so the mass of 
the gasbag is ignored, and the equivalent dynamic model of the fixture double damping is obtained as shown in Fig. 6 show.

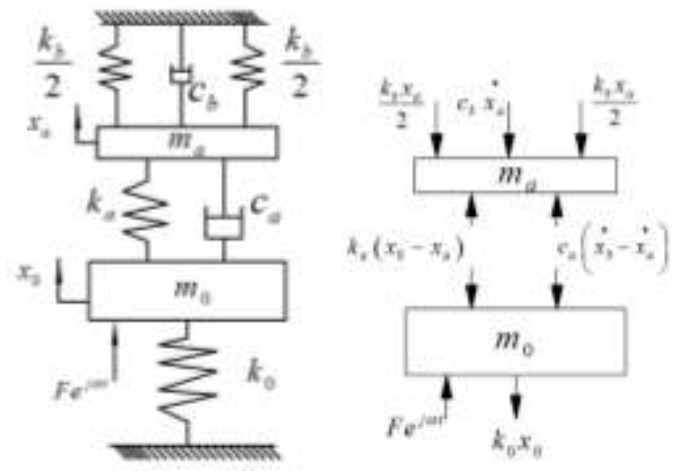

Fig. 6 Equivalent dynamic model of the fixture

The equation of the above dynamic model is shown in equation (11),

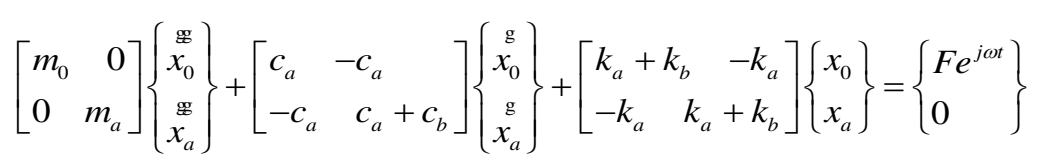

Where, $C_{a}$ and $C_{b}$ are the damping coefficient of the damping components and gasbag; $m_{0}$ and $m_{a}$ are the mass of workpiece and damping components; $k_{0}, k_{a}$ and $k_{b}$ are the stiffness of workpiece, damping components and gasbag; $F e^{j \omega^{t}}$ is the milling force.

Solve Equation (11) with complex number method, and get equation (12) as follows:

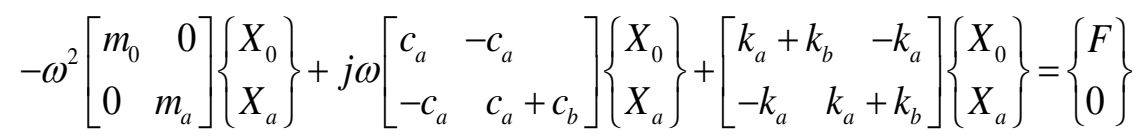

$$
\begin{aligned}
& {\left[Z_{D}(\omega)\right]=[K]-\omega^{2}[M]+j \omega[C]}
\end{aligned}
$$

Where, $\left[Z_{D}(\omega)\right]$ is the system impedance matrix, $[M],[K]$ and $[C]$ are the mass matrix, stiffness matrix and damping matrix. Substituting equation (13) in equation (12), according Cramer rule, we can obtain the displacement amplitude of workpiece and damping components.

$$
\left.\begin{array}{l}
X_{0}=\frac{z_{22} F}{z_{11} z_{22}-z_{12}^{2}} \\
X_{a}=\frac{-z_{21} F}{z_{11} z_{22}-z_{12}{ }^{2}}
\end{array}\right\}
$$

The constant coefficient is shown in Eq.(15)

$$
\left.\begin{array}{l}
z_{11}=k_{0}+k_{a}-\omega^{2} m_{0}+j \omega c_{a} \\
z_{12}=z_{21}=-\left(j \omega c_{a}+k_{a}\right) \\
z_{22}=k_{a}+k_{b}-\omega^{2} m_{a}+j \omega\left(c_{a}+c_{b}\right)
\end{array}\right\}
$$

According to Eq.(15), the vibration amplitude of workpiece-fixture system is affected by a number of factors, for example, self-stiffness of workpiece, the magnitude and frequency of external excitation force, the damping coefficient of gasbag and damping components and so on.

When the system enters the steady response, we can obtain the energy function of system: 


$$
\begin{aligned}
& E_{k}=\frac{1}{2}\left(m_{a} x_{a}^{\frac{\mathrm{g}}{2}}+m_{0} \underset{x_{0}^{2}}{\mathrm{~g}}\right) \\
& E_{p}=\frac{1}{2} k_{0} x_{0}^{2}+\frac{1}{2} k_{a}\left(x_{0}-x_{a}\right)^{2}+\frac{1}{2} k_{b} x_{a}^{2} \\
& E_{l}=\frac{1}{2} c_{0} x_{0}^{\frac{\mathrm{g}}{2}}+\frac{1}{2} c_{a}\left(\stackrel{\mathrm{g}}{\mathrm{g}}_{x_{0}^{2}-x_{a}^{2}}^{2}\right)^{2}+\frac{1}{2} c_{b} x_{a}^{\frac{\mathrm{g}}{2}} \\
& W=F x_{0}
\end{aligned}
$$

Where, $E_{k}$ is kinetic energy of system; $E_{p}$ is potential energy of system; $E_{l}$ is the energy dissipation of the system; $W$ is work done external forces. According to the conservation of energy, when the work done by external forces is constant, the stronger the dissipated energy of the system is, the more potential energy is stored, the smaller the kinetic energy of the system is, and the vibration amplitude will be reduced. This also proves the need to improve the rigidity and damping of thin-walled casing in the machining process.

\section{Workpiece-fixture system dynamics model}

The material of thin-walled casing is titanium alloy (Ti-Al-4V) with physical properties as follows: elastic modulus $113.8 \mathrm{GPa}$, Poisson's ratio 0.3 , and density $4300 \mathrm{~kg} / \mathrm{m}^{3}$. The height of the casing is $430 \mathrm{~mm}$, the inner diameter is $410 \mathrm{~mm}$, the thickness is $4 \mathrm{~mm}$. The material of the foundation is cast iron (HT200), which has excellent casting property and vibration suppression property, the elastic modulus of the foundation is $148 \mathrm{GPa}$, Poisson's ratio 0.25 , the density is 7200 $\mathrm{kg} / \mathrm{m}^{3}$. The material of nylon block is PA66, and the rubber damping material is natural rubber.

\subsection{Model Building}

According to the actual working conditions of the gasbag-rubber damping flexible fixture, the load of the workpiece-fixture system is simplified and equivalent: the pressure of the gasbag is reflected by the spring stiffness coefficient through the relation of displacement after the gasbag is simplified as a spring. The extrusion pressure of the upper pressure plate on the workpiece is replaced by pressure, and the binding constraint is applied to replace the fixation of the bottom Ttype pressure plate on the workpiece. The geometric model of the workpiece-fixture system is shown in Fig. 7.

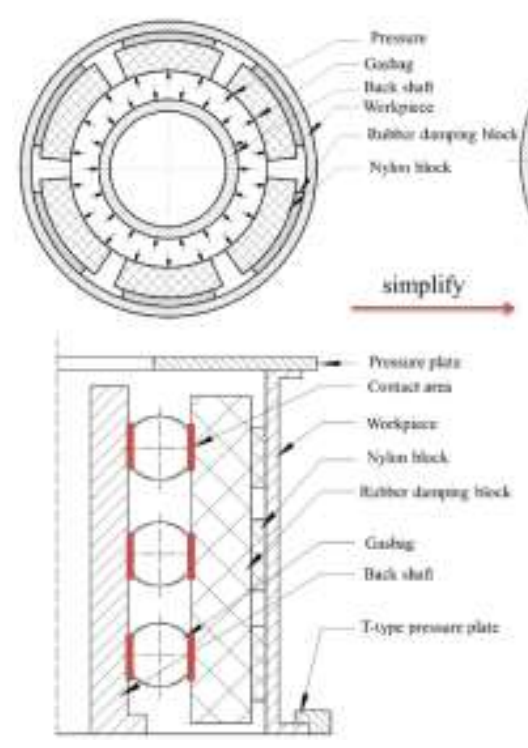

a. Actual conditions

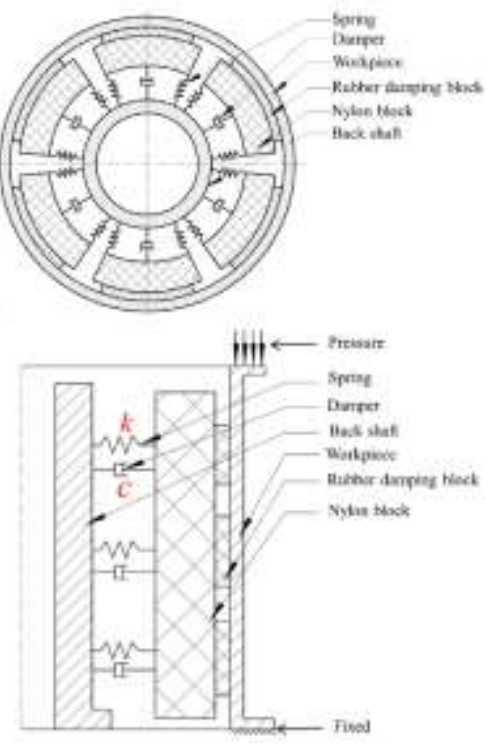

b. Simplified operating conditions

Fig. 7 Geometric model of the workpiece-fixture system 
The gasbag pressure range is $0.01 \sim 0.27 \mathrm{MPa}$, substituting the gasbag pressure into the formula in Section 2.2, the stiffness coefficient of the gasbag simplified to the spring under different pressures can be calculated, as shown in Table 1. Sinusoidal periodic loading milling force is adopted with a frequency of $400 \mathrm{~Hz}$, in the three-directional force, the main cutting force is $637 \mathrm{~N}$, the axial component is $446 \mathrm{~N}$, and the radial component force is $159 \mathrm{~N}$, acted on the nodes of the workpiece milling area. The meshing and boundary condition settings of the dynamic model after the workpiece-fixture system is equivalent are shown in Fig. 8.

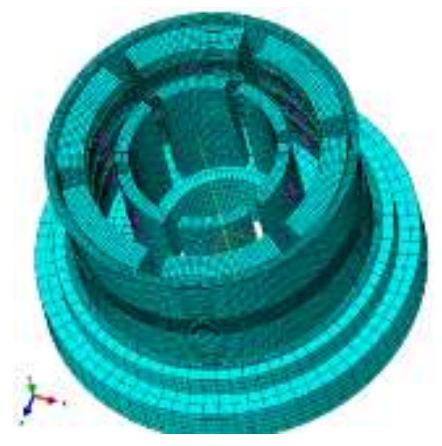

a. Finite element mesh model of flexible fixture

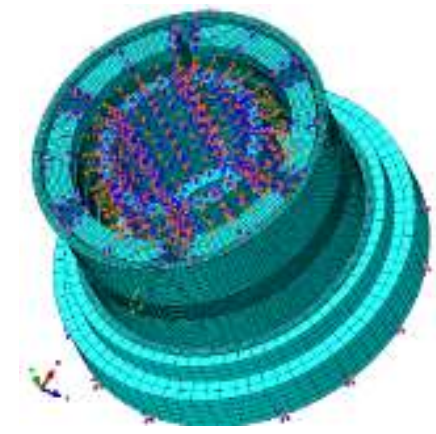

b. Boundary conditions and load of flexible fixture

Fig. 8 Equivalent dynamic model of workpiece-fixture system

Table 1 Stiffness coefficient corresponding to gasbag pressure

\begin{tabular}{cc}
\hline Pressure $(\mathbf{M P a})$ & Stiffness coefficient $\mathbf{k}(\mathbf{N} / \mathbf{m m})$ \\
\hline 0.01 & 15.15 \\
0.03 & 45.43 \\
0.07 & 106.02 \\
0.11 & 166.6 \\
0.15 & 227.19 \\
0.19 & 287.78 \\
0.23 & 348.35 \\
0.27 & 408.94 \\
\hline
\end{tabular}

\subsection{Model verification}

To verify the correctness of the model, milling tests were carried out on TRENT-001 casing on TH65140 machine tool produced by Kunming Machine Tool Co., Ltd. The acceleration of the workpiece was measured by UTEKL signal acquisition and analysis tester of UT3404FRS-DY. Since the upper band of the casing of this model has thin wall thickness, multiple boss features, complex structure, and high machining accuracy is required, the upper band area of the workpiece is selected for machining, as shown in Fig. 9.

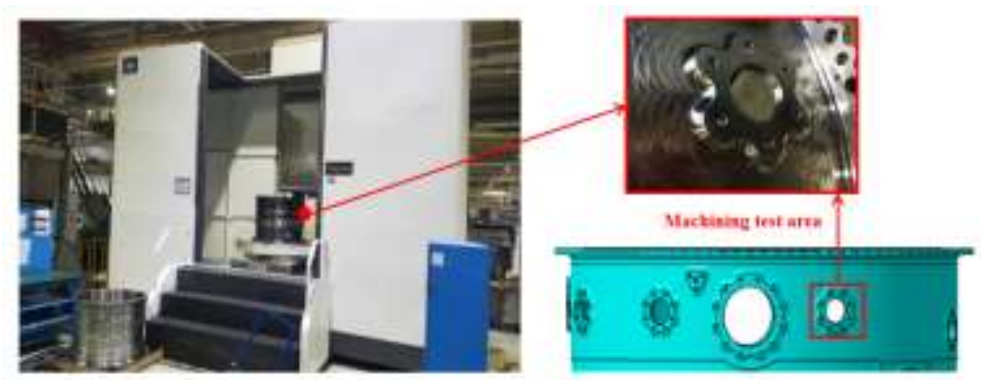

Fig. 9 TRENT-001 casing milling test and machining area

The processing parameters are as follows: the spindle of the machine tool is $6000 \mathrm{r} / \mathrm{min}$. A solid carbide big helix 4 flutes end mill is used for milling, the cutting length of the cutter is $25 \mathrm{~mm}$, the total length of the cutter is $70 \mathrm{~mm}$, and the diameter of the cutter is $10 \mathrm{~mm}$. The working conditions of gasbag-rubber damping flexible fixture are as follows: 
a) The pressure plate presses the upper end surface of the casing;

b) T-type plate fixed the lower end of the casing;

c) Gasbag pressure is $0.048 \mathrm{MPa}$.

The acceleration sensor is installed at the lower side of the milling area, and the vibration signal is collected by the signal acquisition device. Experimental devices are shown in Fig. 10.

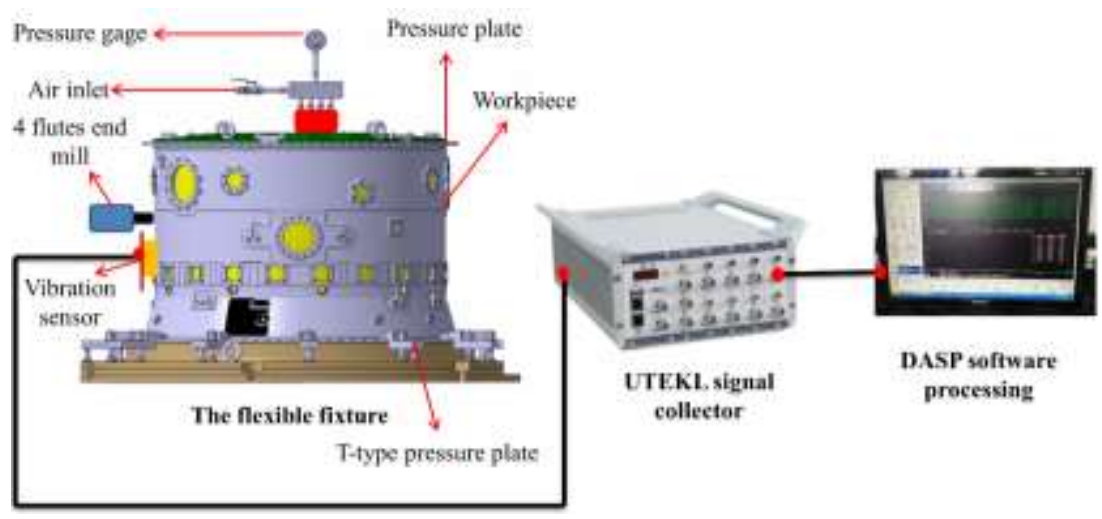

Fig. 10 Experimental device diagram

The vibration data were imported into the DASP software for signal processing, and the acceleration data within 60 seconds when the workpiece entered the stable response was extracted. In order to facilitate the observation and analysis of the vibration law of the casing, vibration signals within 0.3 seconds were intercepted, as shown in Fig. 11.a. It can be seen from the vibration curve of the workpiece in the figure that when the milling process reaches a steady-state response, the vibration of the workpiece presents a sinusoidal trend fluctuation, which proves that it is reasonable to apply a sinusoidal milling force to the model. In order to verify the accuracy of the established equivalent dynamic model of the workpiece-fixture system, the same working conditions as the test are set, and the simulation results are shown in Fig. 11.b.

From Fig. 11 that the vibration law of the workpiece vibration acceleration curve obtained by the milling experiment and the simulation calculation is roughly same. The comparison between the simulation data and the milling experiment data shows that the error of the acceleration root mean square (RMS) is $11.19 \%$, not more than $20 \%$, which shows the accuracy of the calculation results of the equivalent dynamics model of the workpiece-fixture system established in this paper.

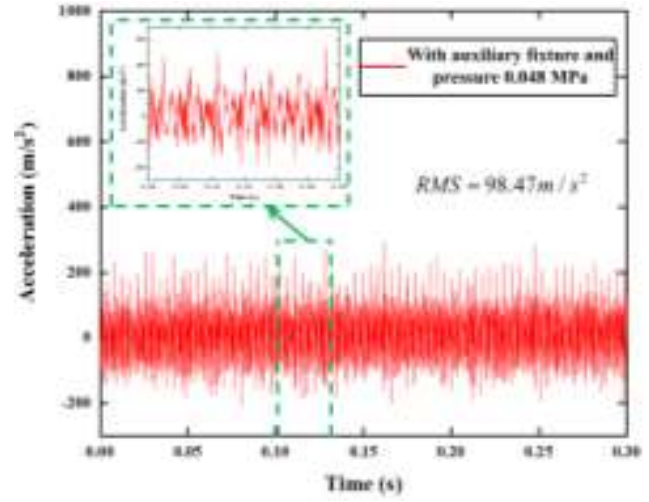

a.Milling test results

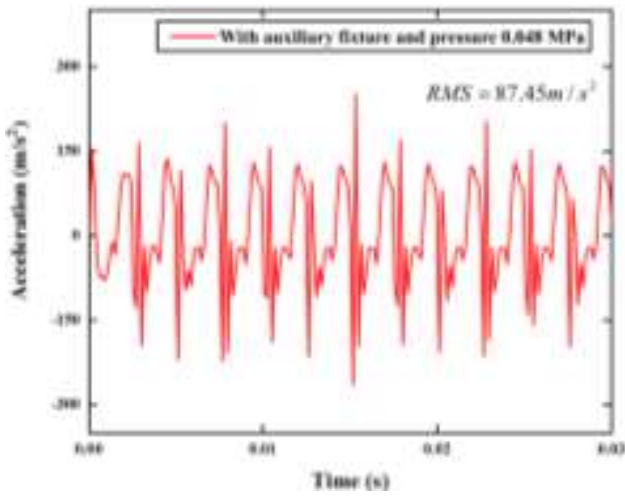

b.Simulation results

Fig. 11 Workpiece acceleration results curve 


\section{Analysis of key factors of workpiece-fixture system vibration}

\subsection{Gasbag pressure}

After the gasbag is pressurized, the rubber damping block will squeeze and support the inner wall of the workpiece, thereby increasing the rigidity of the system. Calculate the Mises stress distribution of the workpiece under different pressures (Fig. 12). From Fig. 12, it can be seen that the stress distribution around the inner wall of the workpiece is uniform and symmetrical, indicating that the rubber damping block is in good contact with the inner wall of the workpiece. As the gasbag pressure increases, the Mises stress on the inner wall of the workpiece also increases, indicating that the stiffness of the workpiece-fixture system has been improved. The following continues to analyze the influence of the gasbag pressure on the vibration acceleration of the workpiece.

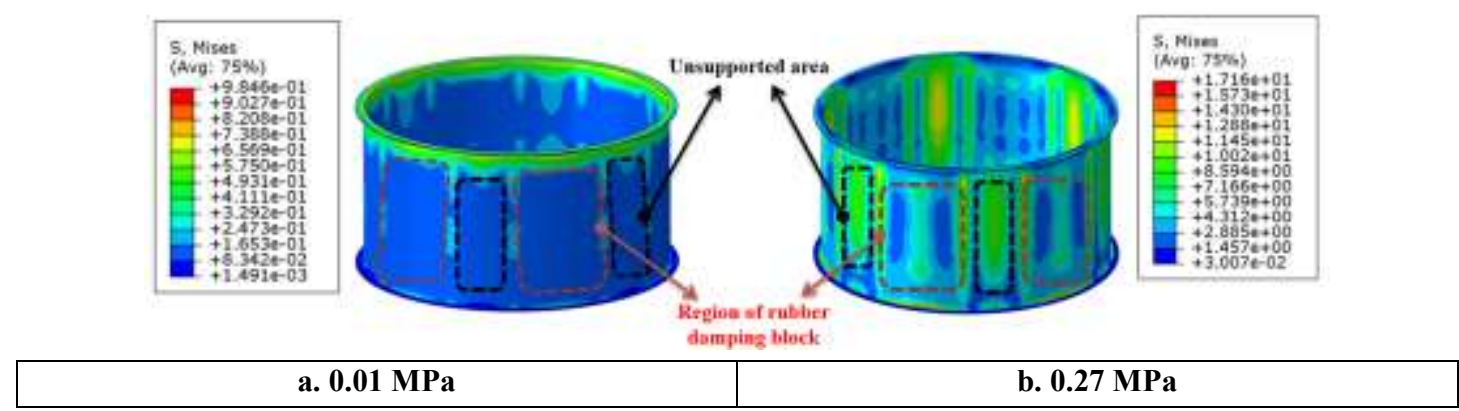

Fig. 12 The cloud map of Mises stress of thin-walled casing

Fig. 13 is the acceleration curve of the workpiece under the pressure of $0.01 \mathrm{MPa}$ and 0.27 MPa. From the vibration acceleration curve of the workpiece, it can be seen that when the milling force acts on the workpiece, the frequency of the workpiece vibration is the same as the periodic frequency of the milling force; When the gasbag pressure is $0.01 \mathrm{MPa}$ (Fig. 13.a), because the radial milling force is greater than the support force of the gasbag on the workpiece, the milling force causes the workpiece to vibrate violently, and the vibration curve is consistent with the trend of the milling force, indicating that the gasbag fixture provides insufficient stiffness and poor vibration reduction effect; As the pressure of the gasbag increases, the support stiffness provided by the fixture for the workpiece increases, and the vibration amplitude of the workpiece decreases (Fig. 13.b).

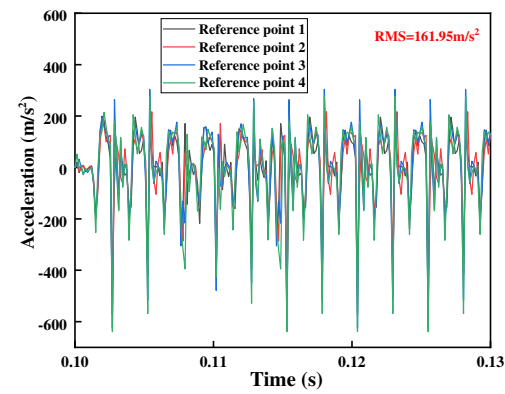

a. 0.01 MPa

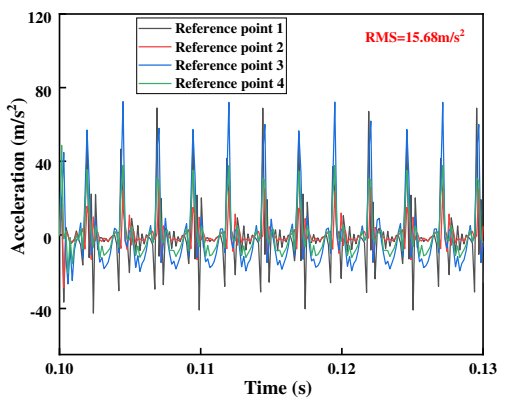

b. 0.27 MPa

Fig. 13 Acceleration curve of reference point on workpiece

Fig. 14 shows the acceleration curves of the workpiece under different pressures. It can be seen from the figure that the vibration intensity of the workpiece decreases with the increase of the pressure of the gasbag. When the pressure rises from $0.01 \mathrm{MPa}$ to $0.27 \mathrm{MPa}$, the acceleration of the workpiece decreases by about 10 times. Although the literature [25] proves that rubber damping materials have a significant damping effect under higher pressure, the large-scale attenuation of workpiece vibration cannot be entirely attributed to its damping effect. Because the response of the 
workpiece under cyclic loading is divided into two parts, one part of the response decreases rapidly with time due to the damping of system, and the other part is forced vibration. In this case, the forced vibration of the workpiece is dominant, so the improvement of damping is of little significance. As the pressure of the gasbag increases, the rigidity contribution provided by the fixture to the system increases, and the vibration amplitude of the workpiece decreases.

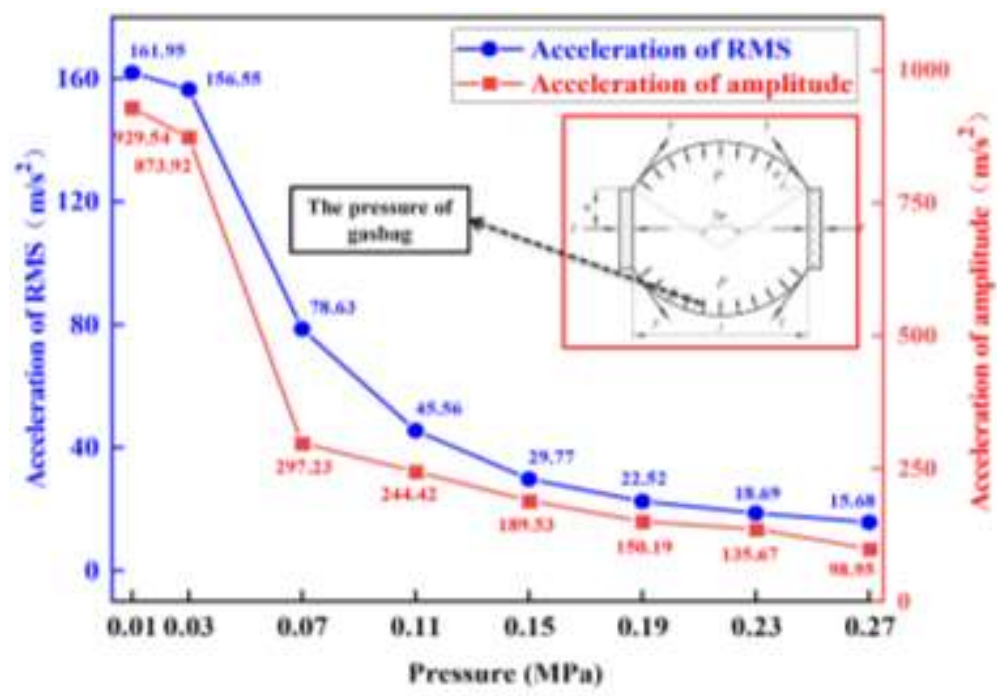

Fig. 14 Effective value and peak of acceleration under different pressures

In practice, the case thickness often changes during the process from blank processing to finished product. For example, the TRENT-001 casing is processed from $400 \mathrm{~kg}$ raw material to $90 \mathrm{~kg}$ finished product, the thinnest part of the wall thickness is $2 \mathrm{~mm}$. Therefore, it is particularly important to select appropriate gasbag pressure for different thickness of the workpiece. Effective acceleration values of the workpiece under different pressures are calculated when the thickness of the workpiece ranges from $2 \mathrm{~mm}$ to $10 \mathrm{~mm}$, and the acceleration curves in Fig. 15 are obtained.

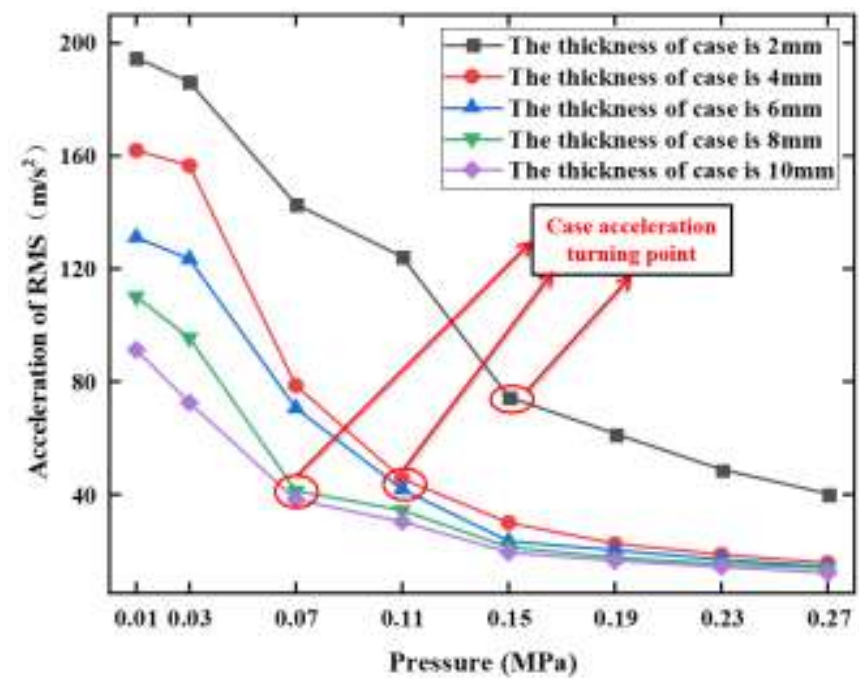

Fig. 15 Sensitivity curve of case thickness to pressure

It can be seen from Fig. 15 that the increase in gasbag pressure is beneficial to reduce the acceleration of the workpiece, but the sensitivity of different workpiece thicknesses to pressure is different. When the workpiece thickness is $8 \mathrm{~mm}, 10 \mathrm{~mm}$, the effective value of acceleration turns at the pressure of $0.07 \mathrm{MPa}$, that is, when the pressure exceeds $0.07 \mathrm{MPa}$, the acceleration curve of the workpiece is relatively gentle, indicating that the machining stiffness of the work-fixture system is enough to resist the external periodic milling force. When the thickness of the workpiece is $4,6 \mathrm{~mm}$ and $2 \mathrm{~mm}$, and the pressure needs to reach $0.11 \mathrm{MPa}$ and $0.15 \mathrm{MPa}$ respectively, the acceleration of 
the workpiece occurs turning point. Therefore, the workpiece thickness and the recommended pressure of the gasbag are shown in Table 2.

Table 2 Recommended pressure corresponding to case thickness

\begin{tabular}{cc}
\hline Case thickness $(\mathbf{m m})$ & Recommended pressure (MPa) \\
\hline 2 & $>0.15$ \\
$4 、 6$ & $>0.11$ \\
$8 、 10$ & $>0.07$ \\
\hline
\end{tabular}

\subsection{Case thickness}

The vibration of thin-walled casing is severe in the processing process, mainly due to the weak rigidity of the workpiece, which is greatly affected by the milling force. Therefore, the thickness of the casing is an important variable of the vibration of the workpiece-fixture system. Only the thickness of the workpiece is changed, and the acceleration curves under different thickness of the workpiece are obtained, as shown in Fig. 16.

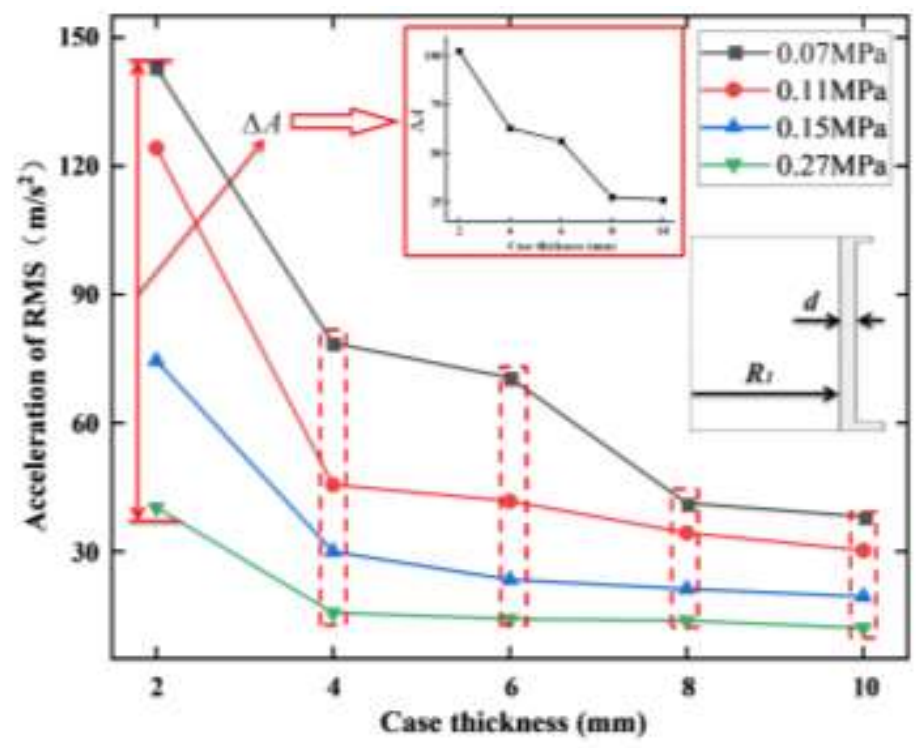

Fig. 16 Acceleration curves with different workpiece thicknesses

Fig. 16 shows that when the workpiece thickness is $2 \mathrm{~mm}$, the vibration of the workpiece is severe and greatly affected by the pressure of the gasbag. The difference of acceleration between $0.07 \mathrm{MPa}$ and $0.27 \mathrm{MPa}$ is $102.59 \mathrm{~m} / \mathrm{s}^{2}$, the reason is that the workpiece stiffness is poor, the milling force work is constant, the system potential energy is small, kinetic energy is large, the workpiece vibration is violent; With the increase of the workpiece thickness, stiffness and system potential energy, the vibration amplitude of the workpiece decreases.

In order to study the influence of case thickness on system stiffness, dynamic milling force was changed to static radial force on the basis of work-fixture system dynamics model, and the displacement at this point was extracted to determine the system stiffness under different casing thicknesses. The calculation result is shown in Fig. 17. It can be seen from the figure that under the same displacement, as the thickness of the receiver increases, the system bears more external static load. 


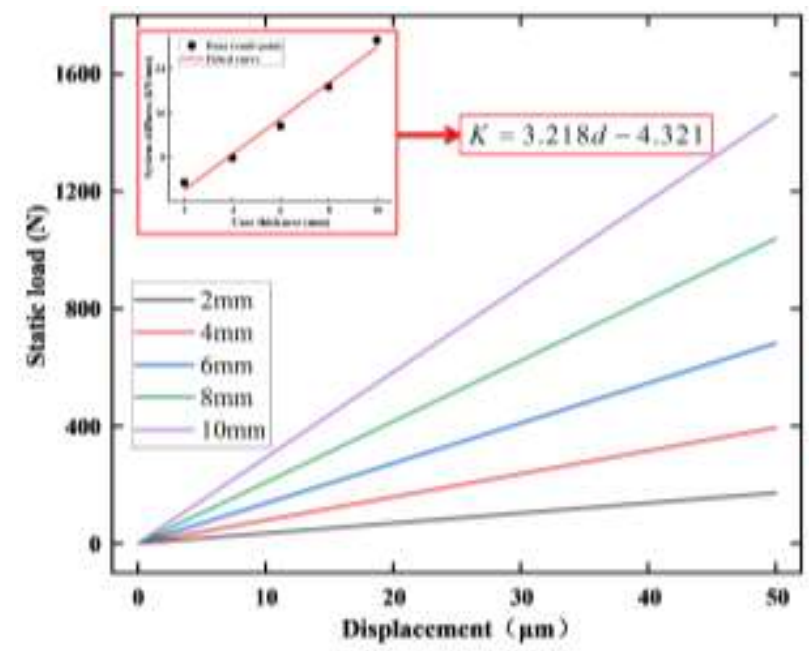

Fig. 17 Stiffness curves of the system with different casing thicknesses

The static load and displacement were substituted into the stiffness calculation formula $K=F / x$, and the stiffness coefficients of the system under different thicknesses were obtained, as shown in Table 3. Based on the scatter diagram of casing thickness and system stiffness coefficient, the function relationship between casing thickness and system stiffness coefficient is obtained by linear fitting as follows: $K=3.218 d-4.321$, where the adjusted $R^{2}$ is 0.985 , indicating that the system stiffness coefficient increases linearly with casing thickness.

Table 3 Stiffness coefficients of the system under different casing thicknesses

\begin{tabular}{cc}
\hline Case Thickness $(\mathbf{m m})$ & Stiffness coefficient $\mathbf{k}(\mathbf{k N} / \mathbf{m m})$ \\
\hline 2 & 3.44 \\
4 & 7.89 \\
6 & 13.65 \\
8 & 20.78 \\
10 & 29.18 \\
\hline
\end{tabular}

\subsection{The thickness of rubber damping block}

In addition to gasbag cushioning and vibration reduction, the damping performance of rubber damping block is also particularly important. The influence of the thickness of rubber damper block on the workpiece acceleration was studied by the workpiece-fixture system dynamics model and the workpiece with thickness of $4 \mathrm{~mm}$ was taken as an example. Vibration curves of the workpiece are shown in Fig. 18. It can be seen from the figure that under different rubber block thicknesses, the law of workpiece acceleration curve remains the same, but there are differences in effective value and amplitude of acceleration. The specific reasons are explained in detail below.

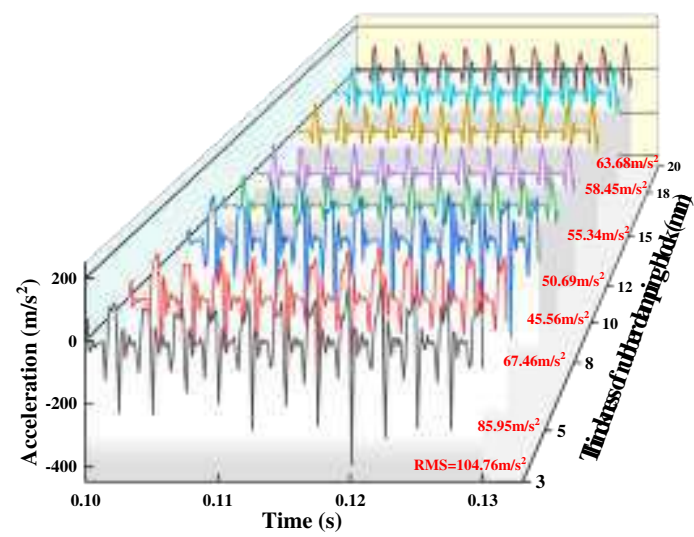

Fig. 18 The average acceleration curves of thin-walled casing under different thickness of damping block 
Extract the effective value and amplitude of the acceleration in the milling area of the workpiece, and draw the curve as shown in Fig. 19.a. From the figure, it can be seen that when the thickness of the rubber damping block is less than $8 \mathrm{~mm}$, the rubber damping block has a limited ability to absorb and consume vibration energy, with the increase of the thickness of the rubber damping block, the vibration energy consumed by the rubber damping block increases, and the amplitude of the workpiece acceleration decreases by $56.82 \%$. When the thickness of the rubber damping block reaches $10 \mathrm{~mm}$, continue to increase its thickness, and the acceleration value of the workpiece shows an increasing trend, because when the airbag pressure is a constant value, the deformation of the damping block decreases as the thickness increases (Fig. 19.b), and its ability to dissipate the vibration energy of the workpiece decreases. Therefore, it is suggested that in actual processing, the thickness of rubber damping block should be controlled within the range of $8 \sim 12 \mathrm{~mm}$.

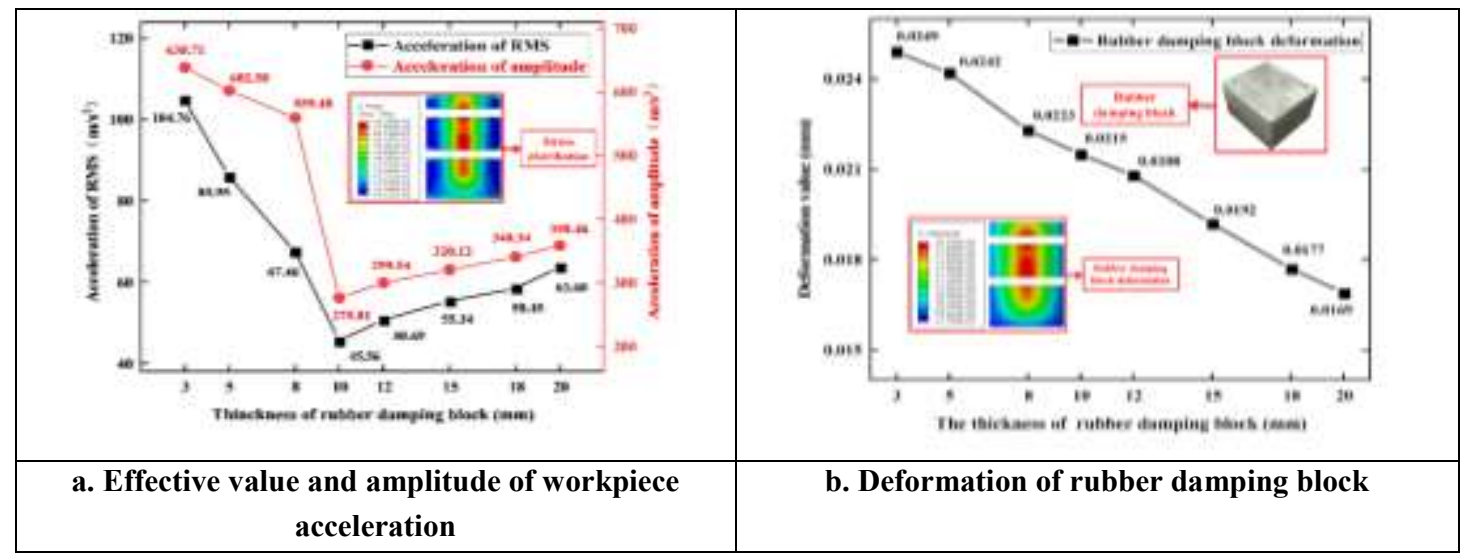

Fig. 19 Curves of workpiece acceleration and rubber deformation under different thicknesses

\section{Conclusions}

In this paper, aiming at the severe vibration and severe tool wear in the machining process of aeroengine combustor casing, a flexible fixture based on gasbag-rubber dual vibration reduction was proposed. By establishing the equivalent dynamic model of workpiece-fixture system, the key factors affecting the vibration of thin-walled casing were analyzed, and the following conclusions are obtained:

(1) According to the similar characteristics of spring and gasbag models, the force of gasbag on nylon block was deduced and calculated by force analysis, and the workpiece-fixture system equivalent dynamic model was established under the action of milling force. The accuracy of the calculation results of the model was verified by the milling test of TRENT-001 casing;

(2) Through the equivalent dynamic model, the influence of the gasbag pressure on the damping performance of fixture is analyzed, and it is found that increasing the gasbag pressure can effectively improve the stiffness of the system, and appropriate gasbag pressure is recommended for different case thickness;

(3) Analyzed the influence of the case thickness on the system rigidity, and pointed out that the casing thickness has a greater influence on the system rigidity, the system stiffness increases linearly with the increase of casing thickness;

(4) The influence of rubber damping block on vibration damping performance of fixture is analyzed, the results show that the damping performance of fixture increases first and then decreases with the increase of the thickness of rubber damping block. It is suggested that the thickness of rubber damping block is $8 \sim 12 \mathrm{~mm}$ in practice. 


\section{Declarations}

\section{Authors' contributions}

Xiaohua Zhu is responsible for paper conception.

Yao Zhang is responsible for writing the draft of the paper and designing the experiment.

Tian $\mathrm{Li}$ is responsible for data the processing of experimental data.

Liangliang Dong is responsible for the derivation of the formula.

Junlei Tang is responsible for providing rubber damping materials.

Shengwei Zhang is responsible for the installation of test equipment.

Funding This work was supported by Sichuan science and technology program (Grant No. 2018CC0098), (Grant No. 2018GZ0429) and (Grant No. 2019YFG0380)

Data availability The datasets generated or analysed during the current study are available from the corresponding author on reasonable request.

Code availability No code were generated or used during the study.

\section{Compliance with ethical standards}

Ethical approval Not applicable

Consent to participate Yes

Consent to publish Yes

Conflict of interest The authors declare that they have no conflict of interest

\section{References}

1. Edhi E, Hoshi T (2002) Stability of high frequency machining vibration by extended chatter model. Precis Eng 26:204-213. https://doi.org/10.1016/S0141-6359(01)00117-9

2. Arnaud L, Gonzalo O, Seguy S, et al (2011) Simulation of low rigidity part machining applied to thin-walled structures. Int J Adv Manuf Technol 54(5-8):479-488. DOI: 10.1007/s00170-010-2976-9.

3. Mañé I, Gagnol V, Bouzgarrou BC, Ray P (2008) Stability-based spindle speed control during flexible workpiece high-speed milling. Int J Mach Tools Manuf 48(2):184-194.

4. Biermann D, Kersting P, Surmann T (2010) A general approach to simulating workpiece vibrations during five-axis milling of turbine blades. CIRP Ann 59(1):125-128.

5. Bravo U, Altuzarra O, López de Lacalle LN, et al (2005) Stability limits of milling considering the flexibility of the workpiece and the machine. Int $J$ Mach Tools Manuf 45:1669-1680. https://doi.org/10.1016/j.ijmachtools.2005.03.004

6. Campa FJ, Lopez de Lacalle LN, Celaya A (2011) Chatter avoidance in the milling of thin floors with bullnose end mills: Model and stability diagrams. Int J Mach Tools Manuf 51:43-53. https://doi.org/10.1016/j.ijmachtools.2010.09.008

7. Adetoro OB, Sim WM, Wen PH (2010) An improved prediction of stability lobes using nonlinear thin wall dynamics. J Mater Process Technol 210(6-7):969-979.

8. Rai JK, Xirouchakis P (2008) Finite element method based machining simulation environment for analyzing part errors induced during milling of thin-walled components. Int J Mach Tools Manuf 48:629-643. https://doi.org/10.1016/j.ijmachtools.2007.11.004

9. GAO Y, MA J, JIA Z, et al. Tool Path Planning and Machining Deformation Compensation in High-Speed Milling for Difficult-to-Machine Material Thin-Walled Parts with Curved Surface[J]. The International Journal of Advanced Manufacturing Technology, 2016, 84(9-12): 1757-1767. DOI:10.1007/s00170-0157825-4.

10. BOLAR G, DAS A, JOSHI S N. Measurement and Analysis of Cutting Force and Product Surface Quality during End-Milling of Thin-Wall Components[J]. Measurement, 2018, 121: 190-204. DOI:10.1016/j.measurement.2018.02.015.

11. Wang S, Jia Z, Lu X, et al (2018) Simultaneous optimization of fixture and cutting parameters of thin-walled workpieces based on particle swarm optimization algorithm. SIMULATION 94:67-76. https://doi.org/10.1177/0037549717713850

12. Zhang FP, Yan Y, Butt SI (2016) Integrated model based thin-walled part machining precision control for the workpiece-fixture system. Int J Adv Manuf Technol 85:1745-1758. https://doi.org/10.1007/s00170-0158036-8 
13. Qin G, Zhang W, Wan M (2006) Analysis and optimal design of fixture clamping sequence. J Manuf Sci Eng 128(2):482-493. https://doi.org/10.1115/1.2162908

14. Wan X-J, Zhang Y, Huang X-D (2013) Investigation of influence of fixture layout on dynamic response of thin-wall multi-framed work-piece in machining. Int $J$ Mach Tools Manuf 75:87-99. https://doi.org/10.1016/j.ijmachtools.2013.09.008

15. Raghu A, Melkote SN (2005) Modeling of workpiece location error due to fixture geometric error and fixtureworkpiece compliance. J Manuf Sci Eng 127(1):75-83. https://doi.org/10.1115/1.1828052

16. Ma J, Zhang D, Wu B, et al (2016) Vibration suppression of thin-walled workpiece machining considering external damping properties based on magnetorheological fluids flexible fixture. Chin J Aeronaut 29:10741083. https://doi.org/10.1016/j.cja.2016.04.017

17. Dong Z, Jiao L, Wang X, et al (2016) FEA-based prediction of machined surface errors for dynamic fixtureworkpiece system during milling process. Int J Adv Manuf Technol 85(1-4):299-315.

18. Selvakumar S, Arulshri KP, Padmanaban KP (2013) Machining fixture layout optimisation using genetic algorithm and artificial neural network. Int J Manuf Res 8:171-195.http://doi.org/10.1504/IJMR.2013.053286

19. Vasundara M, Padmanaban K (2014) Optimization of fixture layout and artificial neural network (ANN) weights of ANN-finite element analysis based fixture layout model using genetic algorithm. J Eng Technol 4(2):102-109.

20. Zeng S, Wan X, Li W, et al (2012) A novel approach to fixture design on suppressing machining vibration of flexible workpiece. Int J Mach Tools Manuf 58:29-43. https://doi.org/10.1016/j.ijmachtools.2012.02.008

21. Kolluru K, Axinte D, Becker A (2013) A solution for minimising vibrations in milling of thin walled casings by applying dampers to workpiece surface.CIRP Ann 62:415-418. https://doi.org/10.1016/j.cirp.2013.03.136

22. Wang X, Ma P, Peng X, Ning S (2020) Study on vibration suppression performance of a flexible fixture for a thin-walled casing. Int J Adv Manuf Technol 106:4281-4291. https://doi.org/10.1007/s00170-019-04696w

23. Yeoh O H(1990) Characterization of elastic properties of carbon-black-filled rubber vulcanizates. Rubber Chemistry and Technology 63:792-805. DOI:10.5254/1.3538289

24. Yeoh O H(1993) Some forms of the strain energy function for rubber. Rubber Chemistry and Technology 66(5): 754-771.

25. Kolluru K, Axinte D (2014) Novel ancillary device for minimising machining vibrations in thin wall assemblies. Int J Mach Tools Manuf 85:79-86. https://doi.org/10.1016/j.ijmachtools.2014.05.007 